\title{
EL PASADO GLORIOSO EN LOS MUSEOS DE LA HABANA: Una propuesta metodológica para su análisis
}

\author{
María Florencia PUEBLA ${ }^{1}$; Jorge Rolando GARCÍA PERDIGÓN ${ }^{2}$ \\ ${ }^{1}$ Escuela Nacional de Antropología e Historia, México. ${ }^{2}$ Museo Nacional de Bellas Artes, La Habana, Cuba \\ pueblaflorencia@hotmail.com,jrperdigon2@yahoo.es
}

THE GLORIOUS PAST IN THE MUSEUM OF THE LA HABANA: A methodological proposal for your analysis

Resumen: Actualmente existe un creciente interés por estudiar las curadurías museológicas, porque simbolizan un aspecto vital en la conformación de identidades ciudadanas del presente. Siguiendo esta idea, se investigaron cuatro espacios museales de la ciudad de La Habana (Cuba), dos que exponen acontecimientos y organizaciones sociales representativos de la Revolución (como el Museo de La Revolución, y el Museo 28 de Septiembre de los Comité de Defensa de la Revolución), y dos que presentan a personajes claves del proceso revolucionario (Museo Casa Natal de José Martí, y Centro Cultural Casa del Che). Se propuso una metodología novedosa que combinó el análisis del discurso, la hermenéutica y la fenomenología. Su aplicación evidenció una explícita tendencia a reforzar una identidad revolucionaria en el presente, mediante la resignificación de un pasado glorioso con el fin de que sean los propios ciudadanos, los que conserven y defiendan al socialismo en el futuro de cambios que se aproxima.

Abstract: There currently exists a growing interest in studying curatorial museology and exhibitions as they symbolize a vital aspect in the formation of the identity of citizens in the present. Following this idea, we investigate four museum spaces in the city of Havana, Cuba. Two that organize exhibitions of historic events and social organizations representative of the revolution (Museum of the Revolution and Museum September 28 of the Committee for the Defense of the Revolution), and two that exhibit key figures of the revolutionary process (Museum Casa Natal of José Martí and the Cultural Center Casa del Che). We propose a new methodology which combines critical discourse analysis, hermeneutics and phenomenology. Its application reveals an explicit tendency to reinforce a revolutionary identity in the present, through the resignification of a glorious past and with the result that Cuban citizens both preserve and defend socialism in the face of future changes.

Palabras clave: Museos. Revolución Cubana. AnÁlisis Del Discurso Curatorial Museums. Cuban Revolution. Analysis Of Curatorial Discourse 


\section{Introducción}

La representación que los museos realizan del pasado es siempre, aunque en forma diferida, un discurso sobre el presente. Esto puede deberse a que muchos de estos discursos se encuentran insertos dentro de las narrativas y construcciones que la sociedad hace de sus identidades y memoria social. Cuando el museo representa al pasado, realiza un discurso museológico del proceso histórico que quiere resaltar, imprimiendo juicios, valores, y posicionamientos ideológicos, que conforman el lineamiento curatorial del museo. De esta manera, se entiende a la curaduría museológica como la práctica encargada del estudio de objetos y narrativas reunidos en un museo, para desarrollar y conceptualizar contenidos expositivos a través de la interpretación de sus valores y significados (Mosco 2012:43 con modificaciones propias). Con el fin de realizar esta tarea, la curaduría comprende un diálogo entre el patrimonio y/o proceso representado, el museo y la sociedad.

Cada representación es una narrativa elegida que se enmarca en un proceso de vinculación del objeto con la idea a escenificar. En el caso de los museos que comprenden acontecimientos históricos, es el pasado el que genera el vínculo con la idea representada (Pearce 1994:27). En este punto, y siguiendo a Susan Pearce (1994), el pasado sobrevive en tres formas distintas: ya sea como objetos, cultura material o patrimonio; como paisaje físico; o como narraciones. Dentro del museo, la curaduría produce una simbiosis de estos tres aspectos, conformando una representación tridimensional del pasado histórico.

Tomando este punto, el presente trabajo desarrolla una propuesta metodológica, que combina el análisis crítico del discurso, la hermenéutica y la fenomenología. Se comienza con una descripción de los museos seleccionados, y cómo se vinculan con el discurso revolucionario nacional. Luego se desarrolla dicha metodología, planteada en tres pasos consecutivos. Finalmente se analiza la información recopilada, y su relación en el contexto de cambios que Cuba transita, y se reflexiona sobre esta propuesta, y su aplicación en el campo museal para generar conocimiento que ayude a comprender con mayor profundidad las narrativas que conforman la identidad histórica y social de La Habana.

\section{Cuatro museos, un mismo pasado}

Para conocer los discursos museológicos del proceso revolucionario en La Habana, se seleccionaron cuatro espacios claves: dos que representan a la Revolución desde una perspectiva procesual, estructural, y sus organizaciones sociales más importantes; y otros dos que exponen desde una perspectiva particular y subjetiva la conformación de la Insurrección independentista. Para la primera se seleccionó el Museo de la Revolución -que refleja todo el proceso revolucionario en una dimensión amplia, desde sus antecedentes hasta la actualidad, destacando sus dirigentes, personalidades y acontecimientos más importantes- y el Museo 28 de Septiembre de los Comité de Defensa de la Revolución -dedicado a la principal organización de masas de la Revolución Cubana, desde su surgimiento el 28 de septiembre de 1960 hasta el presente, exponiendo sus actividades y congresos más representativos-.

Por otro lado, y buscando una perspectiva más particular y subjetiva de este proceso, se seleccionaron dos espacios que exponen a personajes claves. Estos fueron el Museo Casa Natal de José Martí -que presenta la labor intelectual y política del principal ideólogo de la independencia cubana, focalizándose en su ideología antimperialista y anticolonialista-, y Centro Cultural Casa del Che- que destaca la personalidad de Ernesto Guevara, su labor revolucionaria, sus cualidades socialistas, y lealtad a la causa libertaria-. Se seleccionaron estos museos, con la finalidad de tener una visión holística de los discursos del régimen cubano, combinando la perspectiva estructural y dimensional de la Revolución, con personalidades individuales protagonistas de dicho fenómeno. Tanto José Martí como Ernesto Guevara son las figuras revolucionarias más importantes, debido a que aglutinan y representan 
el doble proceso emancipador que tuvo la Isla -primero con España en 1895, y luego con Estados Unidos en 1959-. Siguiendo esto, se realizó un ejercicio museológico que indagó la representación y resignificación desde una metodología que integró tres perspectivas.

\section{Una propuesta metodológica para analizar los discursos museológicos}

Para abordar este estudio, se propuso una metodología que combinó el análisis crítico del discurso expositivo, la hermenéutica, y la fenomenología. Con respecto al análisis crítico del discurso, se puede mencionar que se focaliza en el estudio de acciones sociales que se ponen en práctica a través del discurso, como el ejercicio de configuración social, pero también de poder y control. El discurso se concibe de esta forma como una práctica social con carácter constitutivo propio. Por esto, se considera a esta línea como un ejercicio tridimensional (Martín y Whittaker 1998), que opera simultáneamente en tres direcciones: el discurso como texto, el discurso como práctica discursiva enmarcada en una situación concreta, y el discurso como ejemplo y reflejo de prácticas sociales que no sólo expresan identidades, acciones y relaciones, sino que también las conforman (Iñiguez 2003:94). En el caso del museo, la exposición museográfica es el texto donde se plasma el discurso, que dentro de un espacio -como el museal- desarrolla una práctica discursiva en un ámbito concreto -el museológico-. Todo esto en su conjunto, comprende una praxis social propia de la sociedad en la que se encuentra. Esto último hace referencia a que el museo es por excelencia un espacio social, donde se reconfiguran identidades y alteridades.

Volviendo al plano metodológico, se concibió al discurso como un conjunto de habilidades lingüísticas que mantienen y promueven relaciones sociales (Íñiguez y Antaki 1994:63). El análisis consiste en estudiar cómo estas prácticas actúan en el presente dentro del ámbito social. Es decir, sacar a la luz el poder del lenguaje, como una acción constituyente y regulativa. Si volcamos esto al caso museológico, el rol que tienen los discursos en la conformación de realidades sociales, puede observarse en las categorías de identidad y ciudadanía que el Estado Nación genera y plasma en las narrativas de las exposiciones.

En este punto, resulta interesante destacar la diferencia entre lenguaje y discurso. El discurso es un lenguaje, en tanto que práctica social determinada por estructuras sociales -reglas y/o conjuntos de relaciones de transformación organizadas como propiedades de los sistemas sociales-. Al comprender esto, estamos evidenciando que la estructura social, condiciona la producción de discursos (Íñiguez 2003:118). Con esto, se reconoce que el discurso no es pasivo, sino que también tiene poder agencial dentro de esa estructura social.

Específicamente, un discurso se encuentra formado por un texto -incluyendo imágenes y otro tipo de información que acompaña el relato-, un enunciador y un interlocutor.

No todos los textos constituyen un discurso, sino que se necesitan características y condiciones específicas, como el ser producidos en el marco de instituciones que regulan la propia enunciación -los museos en este caso-, tienen que estar inscritos en un contexto interdiscursivo específico que revelen condiciones históricas, sociales, intelectuales, etc., y se tienen que definir en un espacio social a traves de una identidad propiamente enunciativa (Íñiguez 2003:102). En el caso de estudio tratado aquí la realidad que enuncian las exposiciones seleccionadas -a excepción del Museo Casa Natal de José Martí que expone los antecedentes de este proceso-, hacen referencia a un tiempo histórico fundamental en la constitución política e ideológica de la Cuba, que fue la construcción de un nuevo sistema sociopolítico tras la victoria del poder revolucionario en 1959.

Con respecto al sujeto enunciador/ sujeto locutor, el primero es una realidad empírica, mientras que el enunciador es una construcción textual. El enunciador es el autor y responsable del texto (Íñiguez 2003:103), como son los curadores, historiadores y especialistas, que trabajaron en la conformación curatorial de los discursos expositivos. Sin embargo, no hay que olvidar que estos autores, se encuentran contextualizados por el museo y el Estado 
Nación, que aporta las directrices discursivas.

Con lo mencionado hasta aquí, consideramos que no se puede realizar un análisis del discurso sin tomar en cuenta la hermenéutica. Se entiende a ésta última como la interpretación y comprensión de un texto, que conforma una realidad determinada. Es decir, la hermenéutica no es más que la interpretación de una realidad dada, en cualquiera de sus manifestaciones (Ricoeur 2006). Siguiendo lo anterior, la hermenéutica se constituye como un método interpretativo, que busca establecer un nexo comunicativo entre el texto y el intérprete. Aquí el intérprete se encuentra con una realidad a percibir -la del espacio museal-.

Es reconocido el papel de la fenomenología en trabajos sobre las experiencias sensoriales y corporales que genera una realidad determinada. No obstante, la riqueza conceptual y metodológica de la fenomenología suele quedar relegada en mayor medida a la filosofía fenomenológica, abriéndose escasamente a otros campos disciplinares. Es por esta carencia, que este trabajo pretende entrelazar lazos metodológicos entre esta perspectiva y la museología, buscando un método adecuado para percibir, interpretar y reflexionar sobre un espacio museal concreto. Entendemos como espacio museal a un determinado lugar que mediatiza -o musealiza- una idea por medio de una representación. Siguiendo esto, el espacio museal no siempre comprende una exposición museográfica, ni se encuentra en un museo formalmente constituido, como es el caso del Centro Cultural Casa del Che.

Volviendo al tema de la fenomenología, Husserl la define como un camino para aproximarse a la realidad o a un fenómeno (Husserl 1984). Es decir, es la experiencia de comprender una realidad (Morales 2011), que no es más que un discurso concreto, con un texto, contexto -espacialidad-y sujeto enunciante. En este punto, es conveniente destacar la relación que tienen la fenomenología y la hermenéutica, dos perspectivas que actualmente constituyen un importante foco de estudio dentro de la ciencia contemporánea. Dicho enfoque tiene sus orígenes en el interpretativismo y en la filosofía husserliana. No obstante, en este trabajo, no ahondaremos en propuestas filosóficas (Habermas 1970; Heidegger 1971; Gadamer 1994, 2007; entre otros), sino que la aplicaremos al campo museológico.

La importancia metodológica de la fenomenología y la hermenéutica plantean perspectivas adecuadas para la investigación cualitativa, debido a que se centran en las experiencias vividas, comportamientos, sentimientos, funcionamiento organizacional, discursos, etc. (Morse 2003). Siguiendo esto, su lógica natural se orienta hacia el descubrimiento e interpretación de diversas complejidades y relaciones generadas en una realidad específica (Merleau-Ponty 1997; Strauss y Corbin 2002). Por ende, la relevancia social está contenida en los aportes que proporciona la investigación del humano y la sociedad, debido a que el estudio ofrece una manera diferente de pensar la ciencia social y humanista, y de crear un marco conceptual que permita concebir la complejidad sociocultural a partir de la vivencia y cotidianidad de lo propio (Barbera e Inciarte 2012:201).

Con este esquema teórico, se procedió a diseñar un método que comprende diversas etapas, una introductoria donde se incluyó el contexto museológico, las colecciones y proyecto museal. Luego, se diseñó la primera etapa, que hizo hincapié en el análisis del discurso y la hermenéutica, y consistió en identificar la estructura expositiva, es decir la exposición con sus temas y tópicos principales y segundarios, y sus unidades temáticas. Además, se analizó el patrón de la información contenida en las cédulas -en sus categorías descriptiva, explicativa, reflexiva, interpretativa, etc.-.

En una segunda etapa se utilizó también el análisis del discurso y la hermenéutica, y estuvo basada en identificar el repertorio argumentativo ${ }^{1}$, que fueron los elementos que el enunciador utilizó para construir versiones de la realidad, acciones, procesos cognitivos u otros fenómenos (Wetherell y Potter 1996:66). Esto permitió analizar la secuencia argumentativa y ubicación espacial de temas estratégicos dentro del discurso. Para conocer el

1 término introducido por Potter y Wetherell (1987), en su texto Discourse and Social Psychology. 
repertorio argumentativo en primera instancia se trató de identificar la linea curatorial de la institución, plasmada en las diversas narrativas. En este punto, se analizó la postura del museo con respecto al suceso representado -en este caso la Revolución Cubana de 1959-, luego la posición política frente a determinados acontecimientos y personajes claves de este proceso, y cómo la cultura material expuesta, se insertaba en ese discurso. Aquí se registraron posibles polaridades explícitas/implícitas que tenían que ver con las narrativas maniqueístas propias de los discursos de los Estados Nación. Ejemplo de estos fueron las categorías de buenos/malos reflejadas en: socialistas/imperialistas, capitalistas/anticapitalistas, etc. Por último se registró el promedio de cantidad de información plasmada en las cédulas, el lenguaje utilizado, idioma y los vínculos narrativos entre el pasado y el presente.

El tercero y último paso que comprende esta herramienta metodológica, estuvo dedicado a la parte fenomenológica, y consistió en identificar la experiencia museal. Se describió el entorno ambiental que tenían las exposiciones -iluminación, espacios libres y de descanso, patrones de circulación, focos atencionales, nivel de limpieza, música, y otros elementos que conforman la experiencia museal-. También se reconocieron los soportes y recursos museográficos utilizados, y el tipo de representación -si era ambiental/contextual, emotiva/ sensorial, taxonómica/tipológica, etc.-. Para esto último se realizaron croquis espaciales, con la ubicación de los materiales expuestos. Además se integró a los públicos -condicionantes fundamentales de las experiencias museales-, su sociabilidad dentro del espacio expositivo, las lecturas realizadas en salas y las actitudes manifestadas frente a lo que estaban observando.

Por último, y para terminar, se agregaron comentarios finales, que incluían los aciertos y desaciertos de las exposiciones y sus discursos, la relación con los otros espacios museales seleccionados en el estudio, y si existía una posible conexión con diversas teorías museológicas, como la Nueva Museología o las propuestas que engloban las Museologías Críticas. Toda esta información, fue registrada en fichas de análisis, elaboradas por los autores. Esto permitió una mejor comparación, análisis y reflexión de lo estudiado en cada museo en particular, pero generando articulaciones con los discursos de los otros espacios museales.

\section{La musealización de la Revolución Cubana}

El estudio de los museos seleccionados se llevó a cabo en marzo del año 2016. Comenzamos este análisis con el Museo de la Revolución. Éste es el único espacio museal en la isla que representa de forma cronológica toda la historia revolucionaria.

Contexto museológico: Pertenece al Ministerio de las Fuerzas Armadas Revolucionarias (MINFAR). El museo fue creado en 1959 en la Plaza Cívica, posteriormente llamada Plaza de la Revolución. Más tarde, cuando el gobierno se mudó de sede (año 1965) quedó vacío el edificio presidencial y fue ocupado por el actual museo, abriendo sus puertas en 1974.

Colecciones: surgieron de tres lugares diversos: cuando Celia Sánchez comenzó a reunir diversos objetos que los campesinos y lugareños fueron donando a los revolucionarios cuando estaban luchando en la Sierra Maestra. Además se sumaron las pertenencias personales de éstos guerrilleros. También las Fuerzas Armadas Revolucionarias (FAR) juntaron materiales, y se incluyeron diversos objetos dejados por el gobierno cuando se mudó de edificio. Las colecciones se componen de objetos arqueológicos, históricos -muebles, vestimenta, objetos de guerra, radios móviles, elementos personales de higiene, entre otros-, artísticos - pinturas en su mayoría, esculturas, fotografías, etc.

Proyecto museológico: la primera exposición fue realizada por las FAR. Luego, en la década de los años 1980 se sumaron especialistas que conformaron el guión 
museológico y museográfico actual. Para armar los contenidos de dicha exposición, se basaron en los historiadores Adis Cupul y Froilán González. En el presente se está reestructurando la exposición permanente.

Paso 1: Estructura expositiva:

Exposición: 38 salas de exposición permanente, organizada en tres pisos. $\mathrm{Su}$ línea discursiva es histórico-cronológica, que en la reestructuración no cambiará. Sólo se actualizarán recursos museográficos e incluirán otros contenidos que suman a la comprensión de la Revolución como proceso continuo.

Últimos temas incluidos: la lucha del Che en Bolivia, sala de las personalidades -interés en destacar la figura de la mujer- e información sobre el momento actual de la Revolución.

Cantidad de núcleos temáticos: posiblemente 6 grandes núcleos percibidos.

Temas principales: segundo piso -comienzo de la exposición-: 1. Historia de los primeros pobladores, 2. Asalto al cuartel Moncada, 3. Triunfo de la Revolución: figuras Che y Camilo y su aporte al proceso revolucionario.

Primer piso: 4. La revolución en el poder: medidas revolucionarias, patria o muerte - posicionamiento de Cuba frente a Estados Unidos, base naval Guantánamo, relaciones con EEUU, ataques del imperialismo-, Mártires de Girón -invasión de la CIA a Cuba en el año 1961-, Período 1961 a 1965-, partido comunista-, Período 1965 a 1975 -modelo socialista, estrategia económica, agresividad imperialista- y Período 1975 a 1980 -sala cerrada por nuevo montaje museográfico-.

Nuevos núcleos temáticos: 5. Sala de personalidades: figuras importantes: Carlos M. de Céspedes, Maceo, Gómez, Martí, Camilo, Che, Celia Sánchez, Vilma Espín, etc. 6. Sala del Che en Bolivia: se montó cuando trajeron los restos de Ernesto Guevara.

Otros temas: la relación entre el Che y Camilo Cienfuegos.

Planta baja: Rincón de los cretinos -expuesta desde los años 90 en respuesta a los hechos llevados a cabo por Estados Unidos contra Cuba-.

Exposiciones transitorias: muestra fotográfica Amor a Cuba de Andrej Palacko.

Temas secundarios: Sala monográfica donde se expone la historia del palacio y del museo.

Historia de los combatientes pertenecientes al Directorio Revolucionario que quisieron tomar el palacio en 1957.

Patrón de la información contenida en las cédulas: descriptivas en su mayoría. Articulación de contenidos dados por el orden cronológico.

Paso 2: Repertorio argumentativo:

Elementos constructores de la representación: sucesos históricos dentro de un proceso general aglutinador -revolución de 1959-.

Secuencia argumentativa: cronología del proceso revolucionario.

Ubicación espacial: Distribuída en dos pisos, comenzando desde arriba hacia abajo, siguiendo un orden cronológico lineal. Se utilizaron las antiguas salas del palacio para articular espacialmente el discurso museológico.

Linea curatorial y postura del museo: resaltar lo memorable de la Revolución, los cambios llevados a cabo y la resistencia frente a Estados Unidos. Se percibieron algunas críticas hacia el Partido Comunista -en el núcleo de la revolución en el poder-.

Posición política con respecto a algunos acontecimientos: Énfasis en resaltar la autonomía de la soberanía cubana frente al capitalismo, y valorización de personalidades revolucionarias focalizando en lo heróico de su gesta.

Personajes claves de este proceso: Fidel Castro y los guerrilleros que llevaron a cabo esta gesta. Existe una sala con un montaje más contemporáneo, dedicada 
a estos personajes claves. En ella se exponen -junto con sus objetos personaleslas figuaras de Carlos Manuel de Céspedes -considerado el padre de la patria-, Antonio Maceo Grajales -Para Máximo Gómez su muerte significó la pérdida de la figura más excelsa de la Revolución-, Máximo Gómez -considerado como el primer guerrillero de América-, José Martí -figura universal que llega hasta el presente-, Julio Antonio Mella - uno de los fundadores del Partido Comunista Cubano y ejemplo del hombre que murió por la revolución-, Lázaro Peña González -dirigente obrero y secretario general de la Central de Trabajadores de Cuba-, Ernesto Guevara, Camilo Cienfuegos, Celia Sánchez -la ciudadana más leal, abnegada y fiel- y Vilma Espín -a la que se le otorgó el título de heroína de Cuba-. En el centro de esta sala se encuentra en una vitrina un reloj de pulsera de Carlos Manuel de Céspedes. La única información existente en esta sala es una cédula de pared, con un texto sobre una frase de Fidel, que dice (cita textual): "lo que hicieron aquellos combatientes (...), ha de ser siempre motivo de inspiración para los revolucionarios de hoy ha de ser siempre motivo de confianza de nuestro pueblo, en su fuerza, en su capacidad de lucha, (...) iy que a esta Revolución nada podrá detenerla!" Fidel. Esta sala se encuentra posiblemente dentro del núcleo temático $\mathrm{n}^{\circ} 3$ de la exposición permanente. Es importante mencionar que en la cédula correspondiente a Carlos Manuel de Céspedes, se incluye un comentario de Fidel, donde argumenta que (cita textual): “en Cuba sólo ha habido una revolución: la que comenzó Carlos Manuel de Céspedes el 10 de octubre de 1868 y que nuestro pueblo lleva adelante en estos instantes".

Vínculo entre la cultura material y el discurso: secuencia cronológica. Importancia del suceso histórico y de la personalidad. Los objetos se incluyen en esta línea.

Registro de polaridades: permanente, focalizada en los enemigos de la revolución. Uno de los ejemplos es el famoso rincón de los cretinos donde se exponen los máximos enemigos del régimen: Fulgencio Batista, Ronald Reagan, George Bush padre y George Bush hijo.

Cantidad de información plasmada en las cédulas: 3 párrafos de promedio, con poca información cada uno.

Lenguaje utilizado: informal, frases testimoniales. Nueva cartelería llamativa, con colores vivos y letras grandes.

Idioma: español y en la parte nueva inglés.

Vínculos narrativos entre el pasado y el presente: mantener el recuerdo vivo de lo que costó la Revolución y las grandes personalidades que lo llevaron a cabo, para que su lucha y muerte no sea en vano.

Paso 3: Experiencia museal:

Entorno ambiental: buena luz y amplia movilidad dentro del espacio expositivo, espacios libres en el centro de las salas, casi inexistentes espacios de descanso, patrones de circulación lineales que siguen la secuencia cronológica de la exposición -en las salas, el recorrido es libre-.

Focos atencionales: pocos, debido a la gran cantidad de información y repetición de la naturaleza de los objetos.

Ambiente: limpio, iluminado, sin música. Gran número de visitantes en las diversas salas.

Soportes y recursos museográficos utilizados: panelería, vitrinas de pared en su mayoría, maquetas, imágenes, textos testimoniales, frases de personalidades, etc.

Tipo de representación: histórica/cronológica en la mayoría de la exposición, ambiental/contextual en la sala del Che y Camilo, uso del recurso del humor para representar el Rincón de los cretinos y emotiva en la sala del Che en Bolivia. 
Públicos: de diversas nacionalidades, mucha sociabilidad entre ellos, gran porcentaje de lectura en sala que disminuye a medida que avanza el recorrido, la mayoría de los públicos jóvenes y adultos manifiestan una actitud de estar entretenidos. Realizan estudios de públicos esporádicos -encuestas-.

Comentarios finales:

Es importante mencionar el Memorial Granma, ubicado en la parte externa del museo, donde se encuentra el yate original utilizado por los guerrilleros para llegar a Cuba desde México.

Aciertos: Panelería con información concisa, gran iluminación y libre circulación que permite que las salas no se obstaculicen fácilmente.

Desaciertos: exposición muy larga que causa fatiga museal. No existe una reflexión sobre el proceso revolucionario desde el presente.

Relación con los otros espacios museales: no se incluye explícitamente, pero se manifiesta en un discurso articulado entre los cuatro museos. No se repite información, sino que dependiendo del espacio museal, se especifican temáticas que este museo expone de forma general -ejemplo personalidades individuales y su obra-.

Posible conexión con diversas teorías museológicas: no se evidenciaron.

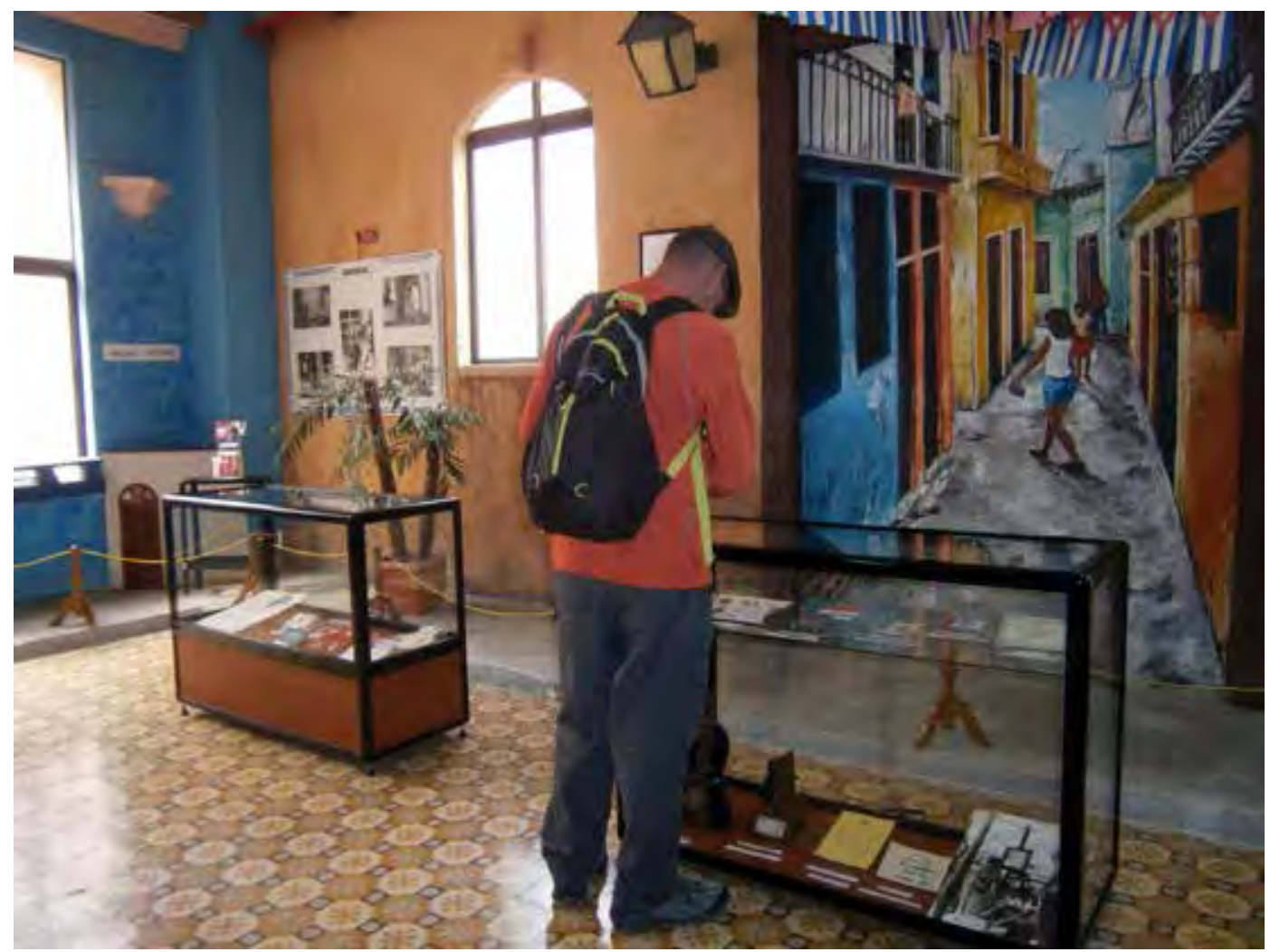

Exposición permanente del Museo 28 de septiembre de los CDR. Imagen propiedad de los autores. 
Museo 28 de Septiembre de los Comité de Defensa de la Revolución. Éste es el único museo que trata todo lo referido a los Comités de Defensa de la Revolución, la organización de masas más numerosa de Cuba.

Contexto museológico: Pertenece a los Comité de Defensa de la Revolución (CDR) y se financia a partir de la donación anual de 3 pesos por cada afiliado al CDR.

Se inauguró en el 2007, siguiendo la idea de Fidel Castro de exponer en un único museo la organización y trabajo de los CDR, además de buscar constituirse como una trinchera ideológica para las actuales y futuras generaciones (Juventud Rebelde 2007).

Colecciones: se formaron por diversas donaciones de los CDR de todas las provincias. Éstos concedieron diversos documentos, fotografías y otros objetos, pertenecientes a sus miembros más destacados.

Proyecto museológico: Para la Coordinación Nacional de los CDR, el museo "debía enseñar no sólo el recuento de la inigualable historia de lucha librada por el pueblo cubano para defender las conquistas de la Revolución, sino también mostrar diversos elementos que motiven a los jóvenes a continuar en los nuevos embates a los que convocan Fidel y Raúl" (Juventud Rebelde 2007).

La exposición fue diseñada por un equipo de museólogos, conservadores y museógrafos pertenecientes al Centro Provincial de Patrimonio Cultural de La Habana, y contiene objetos históricos como medallas, documentos y actas oficiales -carnet fundador original de Fidel Castro por ejemplo-, obras de arte-cuadros pintados y esculturas en su mayoría-, réplicas, objetos personales de afiliados destacados, fotografías originales, etc.

Paso 1: Estructura expositiva:

Exposición: 8 salas distribuidas en 3 pisos. Su línea discursiva es principalmente divulgar y legitimar la importancia del CDR en la actualidad.

Cantidad de núcleos temáticos: posiblemente 10 núcleos percibidos.

Temas principales: Planta baja -comienzo de la exposición- 1. Orígenes: incluye el yate Granma, lucha de Fidel en la Sierra Maestra, asalto al Moncada, entrada de Fidel a La Habana, y éste firmando las primeras leyes revolucionarias. 2. Antecedentes de la revolución: comprende los ataques al socialismo, lucha heroica del pueblo, muertes de los cubanos defendiendo al socialismo, ataque a Playa Girón y estado de alerta de la población por este suceso. 3. Organización: proceso de membrecía, estadísticas de afiliaciones, Segunda Declaración de La Habana, responsabilidades y tareas sociales.

Primer piso: 4. Actividades cotidianas de los CDR en los barrios: festividades, trabajo voluntario -campañas de donación de sangre, limpieza de calles, cuidado del ciudadano, etc., guardias nocturnas-, práctica de la religión afro -santería- y organizaciones de festividades - como la caldosa, en la que se celebra el aniversario de la organización-. 5. Batalla de ideas: incluye el tema de los movimientos antirrevolucionarios, campaña para que liberen los 5 presos cubanos en Estados Unidos y el caso de Elián González.

Exposición temporal: la mujer cubana revolucionaria (anónima), tomada como ejemplo de lucha y de ser humano.

Segundo piso: expone lo más actual de los CDR. Se montó en el año 2013/2014. Los temas que comprenden son: 6. relaciones internacionales de la organización, 7. los CDR en las provincias, 8. El 8vo congreso de la organización, 9. 50to aniversario de los CDR. 10. El museo itinerando por diversas provincias de Cuba.

Temas secundarios: colaboradores de la Revolución: espacio dedicado a Alicia 
Alonso, importante bailarina de ballet cubano, Martí y frases representativas. Dos exposiciones temporales: una dedicada a Hugo Chávez, ex presidente de Venezuela y simpatizante del gobierno cubano - planta baja-y otra a la mujer cubana por el día de la mujer -primer piso-. Exposición anterior dedicada a Alicia Alonso.

La cédula de esta exposición, contiene el siguiente texto (cita textual): "Este mes encierra una fecha muy importante en nuestro país, 8 de marzo, "día internacional de la mujer" que además de festejar, se le rinde homenaje al reconocer el trabajo de las que están esforzándose día a día por mantener los logros alcanzados por la revolución, y recordar a las heroínas que no están con nosotros en estos momentos, pero que brindaron toda su vida por la emancipación de la mujer, por una infancia feliz, además de luchar por la defensa de la patria. La historia también les agradece haber contribuido con su ejemplo a resaltar la imagen combatiente y trabajadora de la mujer. Es común ver a la mujer tomando parte en tareas importantes del país, como directivos, profesionales de la salud, de la educación, en labores agrícolas en las ciencias, en las fuerzas armadas revolucionarias, en el deporte, la cultura y en todos los aspectos de nuestra sociedad. Aprovechando tan hermosa fecha, nuestro museo 28 de Septiembre de los CDR, que a su vez representa a todo nuestro pueblo cederista, rinde homenaje a todas las mujeres de nuestro país. Museóloga: Nery García Medina.”

Patrón de la información contenida en las cédulas: descriptivas en su mayoría, testimonios y frases de personajes célebres (Fidel Castro, Martí, etc.). Falta mucha información, los núcleos temáticos sólo representan los temas, que no van acompañados de una explicación. No se sabe bien a qué hace referencia -recorrido sólo para hacerlo con guía-.

Articulación de contenidos: por categorías temáticas, pero prima un hilo cronológico: desde los primeros años hasta la actualidad.

Paso 2: Repertorio argumentativo:

Elementos constructores de la representación: diversos aspectos que engloban a la cultura cederista (participación y trabajo comunitaria, solidaridad desinteresada, afiliados ejemplares). Foco en los beneficios de la organización social como búsqueda del bien común. Además de que las personas se realizan en el compromiso cotidiano con su comunidad.

Secuencia argumentativa: cronológica, articulada con diversos sucesos y actividades más importantes que dan identidad a los CDR.

Ubicación espacial: temáticas distribuídas cronológicamente en tres pisos, comenzando desde la planta baja.

Linea curatorial y postura del museo: resaltar la importancia del CDR como agrupación social, y su utilidad en el presente. Énfasis en resaltar la participación ciudadana como un valor socialista.

Posición política frente a determinados acontecimientos: clara postura a favor del régimen. Demostración de cómo la sociedad puede defender y continuar cotidianamente con el legado de la revolución. Toman a los enemigos como parte de los elementos que mantienen unido al pueblo cubano.

Personajes claves: Fidel Castro como uno de los miembro más importante del CDR. Alicia Alonso y José Martí.

Vínculo entre la cultura material y el discurso: temática, los objetos expuestos se integran a las diversas temáticas que el museo representa.

Registro de polaridades: algunas evidentes, como una imagen a gran escala con discurso de Fidel, donde menciona a los lacayos imperialistas. En el núcleo 5 -perteneciente a la batalla de ideas- exponen los diversos ataques generados por Estados Unidos hacia la isla (caso de Elián González y los 5 presos cubanos en 
Estados Unidos).

Promedio de cantidad de información plasmada en las cédulas: baja, lectura llevadera, cédulas no saturadas, caligrafía impresa en gran tamaño.

Lenguaje utilizado: prima el informal en calidad de discurso.

Idioma: español e inglés en algunas cédulas.

Vínculos narrativos entre el pasado y el presente: mantener el recuerdo vivo de los orígenes de la Revolución y de los logros sociales alcanzados.

Paso 3: Experiencia museal:

Entorno ambiental: buena luz y amplia movilidad dentro del espacio expositivo, espacios libres en el centro de las salas, inexistentes espacios de descanso, patrones de circulación libres en los diversos pisos.

Focos atencionales: pintura mural a la entrada del Museo, realizado por los artistas Arturo y Leonardo Vázquez -padre e hijo-, primer piso exposición contextual que representa en tamaño real una calle de Cuba, mural en el patio del primer piso.

Ambiente: limpio, iluminado, sin música. Pocos visitantes en el momento del estudio. No buena circulación en el segundo piso.

Soportes y recursos museográficos utilizados: panelería, vitrinas, video sobre la historia de los comités, escenografías a gran escala, imágenes a gran escala.

Tipo de representación: ambiental/contextual en todo el segundo piso -núcleo 4 de las actividades de los CDR-.

Públicos: en el momento del estudio, todos extranjeros -se encuentra en el andador más turístico de La Habana-. Poca socialibidad, todos iban con guía. Se encontraba mayor cantidad de gente en la tienda, ubicada a la entrada del museo.

Comentarios finales:

Aciertos: La representación del barrio en el primer piso, desestructura el museo, le aporta un gran foco atencional a la exposición, allí cambia la museografía. Uso de gigantografías y de obras e arte. A la exposición del segundo piso se le realiza una remodelación museográfica y se le quitan varias fotos, debido a la gran cantidad que se encontraban expuestas.

Desaciertos: el resto de la exposición presenta objetos que no se encuentran bien musealizados. Falta de reflexión crítica. Poca información en todo el museo, los públicos tienen que interpretar por sí solos, buscar la conexión, y específicamente qué son los CDR. Esto evidencia que es un museo pensado para el cubano, que para el extranjero.

Relación con los otros espacios museales: no existe.

Posible conexión con diversas teorías museológicas: no se incluyen.

Museo Casa Natal de José Martí. Expone la vida y obra del libertador cubano contra el poder colonial español. Contiene la mayor cantidad de objetos personales de Martí.

Contexto museológico: Pertenece a la Oficina del Historiador de la Ciudad (OHC) de la Habana. Abrió sus puertas en el año 1925, siendo uno de los más antiguos museos de La Habana. En 1949 y 1978 el edificio fue declarado dos veces Monumento Nacional. A partir del centenario Martí, en 1953 se constituye la generación del Centenario, inspirada en el ideario Martiano. Ésta es la generación que ideó el asalto al Cuartel Moncada -Santiago- y Cuartel Carlos Manuel de Céspedes -Bayamo-. Fidel Castro en su defensa argumenta que Martí fue el autor intelectual del movimiento 26 de julio y de los asaltos. Por esto, se lo vinculó política e ideológicamente con la revolución de 1959.

Colecciones: se conformaron por donaciones de familiares y descendientes, 
así como de amistades y colaboradores de la gesta revolucionaria contra España. Además de donaciones que realizan otros museos. No hay documentos originales, éstos se encuentran resguardados en la Oficina de Asuntos Históricos del Consejo de Estado.

Objetos personales, muebles históricos, vajilla original de la casa, reproducciones de barcos, documentos, cartas personales, mobiliario educativo y reproducción de fotografías históricas.

Proyecto museológico: realizado por museólogos del lugar. El equipo de museógrafos pertenecía a la Dirección de Patrimonio Cultural de la Oficina del Historiador de la Ciudad. Actualmente se encuentra aprobado un nuevo guión museológico, que en la época del estudio aún no se encontraba montado.

Paso 1: Estructura expositiva:

Exposición: Realizada en 1997 por José Linares, reconocido museógrafo cubano. Cuenta con 8 salas de exposición, organizada en dos pisos. Su línea discursiva es histórico-cronológica: representación de las diversas etapas de su vida.

Cantidad de núcleos temáticos: posiblemente 7 núcleos percibidos.

Temas principales: primer piso -comienzo de la exposición- 1. Nacimiento y juventud: contiene temas referidos a su nacimiento, bautizo, ambiente familiar, sus primeros estudios y labor revolucionaria hasta su deportación a España. 2. Deportación a España: Su paso por este país, Estados Unidos y México, su vida en Guatemala y su casamiento.

Patio: 3: Regreso a Cuba en 1878: su paternidad, actividad revolucionaria y partida a España.

Cuarto planta alta del patio: 4: estancia en Tampa, Florida.

Planta baja: 5. viajes: España, Estados Unidos, su estancia en Venezuela, actividad diplomática como representante de Uruguay y Paraguay en Nueva York. 6. Preparación de la guerra necesaria: constitución del Partido Revolucionario $\mathrm{Cu}$ bano y de los clubes revolucionarios, regalos en sus estancias en el extranjero. 7. Desembarco en Cuba y caída en combate.

Temas secundarios: reproducción de su oficina.

Patrón de la información contenida en las cédulas: muy poca información, no hay cédulas temáticas, sólo de pie de objetos que son descriptivas en su mayoría. Articulación de contenidos dados por el orden cronológico.

Paso 2: Repertorio argumentativo:

Elementos constructores de la representación: sucesos históricos que van armando su vida personal.

Secuencia argumentativa: cronológica, desde su nacimiento hasta su muerte.

Ubicación espacial: Distribuída en dos pisos, comenzando desde arriba hacia abajo, siguiendo un orden cronológico lineal. Se utilizaron las antiguas salas de la casa histórica.

Linea curatorial y postura del museo: resaltar la vida y obra de José Martí, sus ideales y lucha por la emancipación de España. Tomado como el primer revolucionario.

Posición política frente a determinados acontecimientos: Énfasis en resaltar el esfuerzo permanente de Martí por liberar Cuba.

Personajes claves de este proceso: sólo José Martí.

Vínculo entre la cultura material y el discurso: importancia de la colección, a partir de los objetos personales se articuló el recorrido, siguiendo una secuencia cronológica.

Registro de polaridades: no se registraron.

Promedio de cantidad de información plasmada en las cédulas: sólo cédulas de 
objetos.

Lenguaje utilizado: coloquial, descripción.

Idioma: español.

Vínculos narrativos entre el pasado y el presente: mantener el recuerdo vivo de lo que le costó a Martí llevar a cabo la primera liberación de Cuba. Énfasis de su esfuerzo personal por una causa nacional.

Paso 3: Experiencia museal:

Entorno ambiental: buena luz, se utilizó la casa antigua que se encuentra muy bien restaurada. Se sigue un orden de visita, que va desde el primer piso, patio y planta baja. Patrones de circulación lineales que siguen la secuencia cronológica de la exposición -en las salas el recorrido es libre-.

Focos atencionales: reconstrucción de la habitación, cuadros.

Ambiente: limpio, iluminado, sin música. Pocos visitantes en las diversas salas.

Soportes y recursos museográficos utilizados: vitrinas y paneles de pared en su mayoría, muchas imágenes, cartas.

Tipo de representación: histórica/cronológica en toda la exposición.

Públicos: sólo tres en el momento del estudio. Sociabilidad en lo que podría ser una madre con su hija. Realizan actividades con diversas escuelas del país.

Comentarios finales:

Aciertos: la casa se encuentra muy bien restaurada. Tienen programas escolares que desarrollan en el patio trasero de la vivienda.

Desaciertos: Falta mucha información contextual de la vida de Martí.

Relación con los otros espacios museales: no se percibió.

Posible conexión con diversas teorías museológicas: no se evidenciaron.

Centro Cultural Casa del Che, se encuentra dentro del Complejo de Museos Históricos Militares, en el Parque Histórico Militar Morro-Cabaña, próximo a la localidad de Casablanca. El inmueble que ocupa actualmente el museo fue la primera casa que ocupó Guevara en 1959, cuando llega a La Habana. Es el único museo en La Habana dedicado exclusivamente a exponer la figura del Che.

Contexto museológico: Pertenece al Ministerio de las Fuerzas Armadas Revolucionarias (MINFAR). Se inaugura como museo en el año 1970. Luego fue reparada en 2006, reinaugurándose a fines de año como Centro Cultural Casa del Che en La Cabaña.

Colecciones: provenientes de los fondos del Museo de la Revolución y donaciones recibidas. Fotos históricas, muebles antiguos de casa, objetos personales de los guerrilleros -ropa, máquina de escribir, cámara de fotos antigua, radio móvil, camilla y elementos de medicina, etc.-, objetos de uso cotidiano -vajilla, etc. -, cuadros de diversos artistas cubanos, etc.

Proyecto museológico: la exposición fue realizada por museólogos provenientes de este espacio, y por el personal de apoyo del Museo de la Revolución.

Paso 1: Estructura expositiva:

Exposición: 7 salas de exposición, organizada en planta baja. Su línea discursiva es temática sobre la vida del Che y sus cualidades más importantes.

Cantidad de núcleos temáticos: posiblemente 4 núcleos percibidos.

Temas: 1. Su trabajo -debate e implementación de las reformas que llevó a cabo la Revolución, casa como espacio laboral, visitas de otros líderes-, 2. Su habitación y su enfermedad -asma-, 3. el Che y su deseo constante de aprender-manifestado en el ajedrez y la lectura-, 4. Guerrilla en Bolivia, 5. Muerte y ejemplo de lucha -con el féretro original con el que trasladaron el cuerpo de Guevara de Bolivia a 


\section{La Habana-.}

Temas secundarios: Sala de protocolo: visita de Raúl Castro al lugar, cuadros sobre el Che.

Patrón de la información contenida en las cédulas: descriptivas en su mayoría. Articulación de contenidos dados por la vida del Che.

Paso 2: Repertorio argumentativo:

Elementos constructores de la representación: temático, dependiendo de las colecciones.

Secuencia argumentativa: la vida como guerrillero y político de Ernesto Guevara.

Ubicación espacial: Distribuída en todas las habitaciones de la casa de la planta baja. No se sigue un orden secuencial.

Linea curatorial y postura del museo: resaltar lo memorable de la personalidad de Ernesto Guevara, su compromiso con la revolución y su obra, como ejemplo del ciudadano socialista.

Posición política frente a determinados acontecimientos: valorización de su personalidad en combate y en la política.

Personajes claves de este proceso: Fidel Castro comentando las cualidades ejemplares de Guevara, Raúl Castro visitando el espacio. La cédula de esta exposición, contienen los siguientes texto (cita textual): Si queremos expresar cómo aspiramos que sean nuestros combatientes revolucionarios, nuestros militantes, nuestros hombres, debemos decir sin vacilación de ninguna indole: ique sean como el Che! Fidel.

Che está ganando y librando más batallas que nunca. Gracias Che, por tu historia, tu vida y tu ejemplo. Fidel

Vínculo entre la cultura material y el discurso: por temas.

Registro de polaridades: no se identificaron.

Promedio de cantidad de información plasmada en las cédulas: poca. Un párrafo.

Lenguaje utilizado: coloquial, descripción, letras grandes, cartelería llamativa, con colores vivos.

Idioma: español e ingles.

Vínculos narrativos entre el pasado y el presente: mantener el recuerdo vivo de Ernestro Guevara como ejemplo del ciudadano socialista, para que su lucha y muerte no sea en vano.

Paso 3: Experiencia museal:

Entorno ambiental: buena luz y amplia movilidad dentro del espacio expositivo, espacios libres en el centro de las salas, casi inexistentes espacios de descanso, patrones de circulación lineales que siguen la secuencia cronológica de la exposición -en las salas el recorrido es libre-.

Focos atencionales: pocos, debido a la gran cantidad de información y repetición de objetos, Ambiente: limpio, iluminado, sin música.

Soportes y recursos museográficos utilizados: panelería, vitrinas de pared en su mayoría, maquetas, imágenes, textos testimoniales, frases de las personalidades, etc.

Tipo de representación: ambiental/contextual en las reconstrucciones de la oficina y dormitorio. Emotiva en la caída y muerte.

Soportes y recursos museográficos utilizados: vitrinas, panelería, cédulas de vitrina y de objeto.

Públicos: pocos - pudo deberse a que no se encuentra en el centro de la Ciudad, y su entrada en comparación a otros espacios museales, es más costosa: 6 CUC-. 
Los pocos públicos eran de diversas nacionalidades, poca sociabilidad entre ellos, bajo porcentaje de lectura en sala que disminuye a medida que avanza el recorrido.

Comentarios finales:

Aciertos: Buena selección de los temas principales de la vida de Guevara. Panelería con información concisa, luminación y libre circulación que permite que las salas no se obstaculicen fácilmente.

Desaciertos: Poca información, los visitantes tienen que interpretar muchas cosas. Es para un público conocedor de la vida y obra del personaje representado.

Relación con los otros espacios museales: no se incluyen explícitamente, pero se manifiesta en un discurso articulado entre los cuatro museos, dentro de un proceso revolucionario en el que se destacó la personalidad de Guevara.

Posible conexión con diversas teorías museológicas: no se evidenciaron.

\section{Reconstruyendo el pasado desde los museos de La Habana}

Las profundas transformaciones socio-económicas y políticas emprendidas por la Revolución Cubana, conformaron una sociedad en búsqueda permanente de una realización ciudadana (Martínez 2016). Se pretendía generar una nueva realidad patrimonial que incluyera los valores emancipadores creados por el nuevo socialismo que se estaba construyendo. Los museos no escaparon a este proceso, y fueron reestructurados a través de una ley de iniciativa estatal (Ley No. 23/1979), que los ordenó en el territorio nacional. En esto, se sumo una entusiasta población, que participó de forma activa en la conformación de nuevas colecciones patrimoniales.

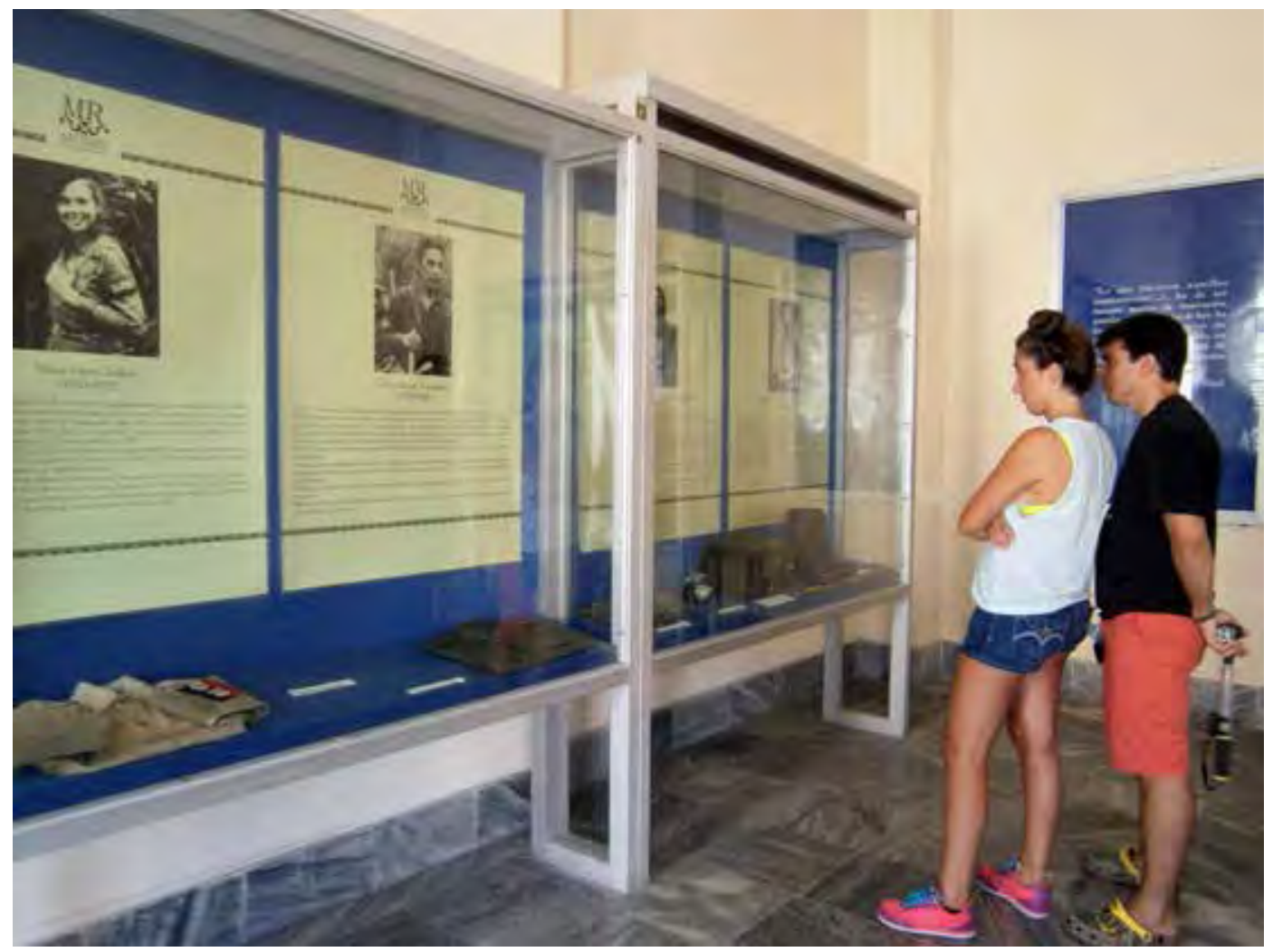

Públicos en la Sala de los personajes claves, Museo de la Revolución. Imagen propiedad de los autores. 
La nueva etapa, propuso una nueva identidad en la relación museo-sociedad cubana, que junto con una organizada programación cultural, fueron la base de la socialización del patrimonio (García 2014:73). Actividad que estuvo vinculado a la formación política-ideológica y patriótico-militar que los museos imprimieron en las nuevas generaciones, con el objetivo de mantener vivo el espíritu socialista. En el presente, esta formación continúa bajo el Sistema Nacional de Museos de la República de Cuba (Ley No. 106/2009). Éste constituye el mecanismo de integración y promoción de la cultura y patrimonio insular, con la finalidad de lograr su protección, conservación y divulgación. En este sistema se insertan los cuatro espacios analizados, que como se pudo observar en el estudio mantienen diferencias, pero se encuentran articulados por una línea temática nuclear que es el proceso revolucionario en su dimensión amplia.

Comenzando con el Museo de la Revolución, el análisis evidenció que éste representa las diversas etapas revolucionarias, con la finalidad de resaltarlo como fenómeno extraordinario del mundo y de la historia de Cuba. Como se menciona en la sala de los personajes claves, este proceso no comenzó en 1959, sino - como indica Fidel- en 1868 con Carlos Manuel de Céspedes, y continúa hasta el presente con el pueblo contemporáneo. Los personajes en esta sala representados -Antonio Maceo Grajales, Máximo Gómez, José Martí, Julio Antonio Mella, Lázaro Peña González, Ernesto Guevara, Camilo Cienfuegos, Celia Sánchez y Vilma Espín- son parte fundamental de este proceso revolucionario de largo alcance, y en el presente son resignificados como un ejemplo de lucha y ciudadanía socialista.

A esto se suma la mención de la embestida que en 1957 realizó el grupo conocido como Directorio Revolucionario, con el fin de derrocar a la dictadura de Batista. Con esto se demuestra que la revolución era un fenómeno inevitable en la historia de Cuba -quien sea que la dirija-, y que comprende un proceso social más amplio y profundo, que el desarrollado en 1959. También se mencionaron algunas críticas hacia el antiguo Partido Comunista, que tuvieron que ver con el ejercicio del gobierno democrático, y al régimen socialista, vinculadas con errores que se cometieron en la primera parte del gobierno.

Desde otra perspectiva, el Museo 28 de Septiembre de los Comité de Defensa de la Revolución, está dedicado a representar la principal organización de masas de la Revolución Cubana, desde sus antecedentes y surgimiento el 28 de septiembre de 1960 hasta el presente, exponiendo sus actividades sociales más importantes, los congresos y reuniones memorables y las relaciones que esta organización mantiene a nivel nacional e internacional. Como bien menciona Dora Pérez Sáez, este museo:

"se crea con la finalidad de ser una trinchera ideológica para las actuales y futuras generaciones, además de exponer no sólo el recuento de la inigualable historia de lucha librada por el pueblo cubano para defender las conquistas de la Revolución, sino también para mostrar diversos elementos que motiven a los jóvenes a continuar en los nuevos embates a los que convocan Fidel y Raúl" (Pérez 2007).

Con esta cita, queda explícita la función principal de este espacio, destinado en mayor medida al pueblo cubano, más que a los visitantes extranjeros. Esto último puede relacionarse a la poca información explayada en la exposición, que pareciera estar destinada a públicos conocedores y con experiencia en los CDR. Lo mencionado se afianza con que por otro lado expone el museo, esto es que la revolución es una actividad de compromiso cotidiano diario, donde todos los habitantes de la isla tienen tareas específicas que cumplir según su edad. Los mayores deben participar en diversas labores y campañas de beneficio común -congresos, donación de sangre, etc. -, y el trabajo voluntario en su contexto social -limpieza y conservación de casas, organización de actividades barriales, fiestas populares, etc.-. Estas eran dos de las cualidades evidentes que el Che Guevara demostraba constan- 
temente a lo largo de su vida -y que se encuentran bien representadas en el Centro Cultural Casa del Che, como una muestra de su compromiso revolucionario-. Por otro lado, los niños tienen que asistir al plan de la Calle, un programa de actividades recreacionales y lúdicos destinado a la población infantil, y que se encuentra enmarcado en una base teórica pedagógica concreta (Ecured s/f). Con esto, el Museo 28 de Septiembre explicita que la revolución es una tarea de compromiso diario de todos los sectores de la sociedad cubana, cada uno desde el papel que le toca.

Por otro lado, los cuatro museos, pero más que nada el de la Revolución y el 28 de Septiembre, evidencian explícitos registro de polaridades, todas focalizadas en los enemigos de la revolución. Esto puede observarse en los diversos adjetivos despectivos que se exponen en las narrativas museales, en su mayoría dedicados a Estados Unidos, en calidad de respuesta a sus múltiples ataques militares, económicos y culturales. El ejemplo más representativo es el ya mencionado Rincón de los Cretinos, ubicado en la planta baja del Museo de la Revolución. También se evidencia permanentemente la agresión que realiza el país del norte, y la respuesta del pueblo cubano. El más importante es el fenómeno llamado Batalla de ideas -expuesto claramente en el Museo 28 de Septiembre-, que incluye el tema de las acciones contrarrevolucionarias, la constante campaña cubana para que Estados Unidos libere a los 5 presos cubanos y el conocido caso de Elián González. Aquí se hace un fuerte hincapié en que la batalla de ideas es en defensa de los ideales socialistas, y que son éstos los que mantendrán unido al pueblo cubano en el presente y en el futuro. Lo mencionado se conecta con los otros dos museos analizados, donde se exponen que tanto Martí como Guevara perdieron su vida en la defensa de estos ideales. El fin de exponer estas polaridades de revolucionarios/contrarrevolucionarios podría evidenciar un intento por generar un sentido aglutinador y de pertenencia social en el presente, así como procesos de identidad y alteridad de lo que son los cubanos y lo que no quieren ser.

Asimismo, se incorporaron en los últimos tiempos, actores sociales antes marginados, como son las mujeres; valorizando por primera vez sus cualidades como revolucionarias, diferentes a las de los hombres. En los museos se hace alusión al papel de la mujer como una luchadora social y como ejemplo de ciudadana socialista. También se incorporaron otras temáticas que demuestran la mirada de hermandad con Latinoamérica. Se introdujo en el Museo de la Revolución la lucha encabezada por el Che en Bolivia, para afianzar su internacionalismo y su solidaridad hacia todos los pueblos oprimidos. Además se suman las exposiciones temporales llevadas a cabo en el Museo de los CDR, donde se exponen los amigos del pueblo cubano, como por ejemplo el ex presidente de Venezuela Hugo Chávez.

Los museos Museo Casa Natal de José Martí, y Centro Cultural Casa del Che exponen una perspectiva más particular y subjetiva de este proceso. En el primer caso, el museo está focalizado a públicos cubano, debido a que no existe información sobre la vida de este personaje que pudiese contextualizar a un visitante desconocedor. El fin de su exposición es presentar la labor intelectual y política del principal ideólogo de la independencia cubana, focalizándose en su pensamiento antiimperialista y anticolonialista. Asimismo, el Centro Cultural Casa del Che destaca la personalidad de Guevara, su labor y cualidades socialistas, y lealtad a la causa libertaria. Estas dos figuras integran el panteón de los héroes revolucionarios, junto con otras figuras emblemáticas. Todos ellos destacados por diferentes valores y labores, como bien lo grafica la sala de personajes claves en el Museo de La Revolución, mencionada anteriormente.

Los discursos museológicos remarcan diversos aspectos de cada personaje. El caso de Guevara y Cienfuegos es un ejemplo de ello. Siempre evidenciando la relación de amistad que existían entre estos dos y con Fidel, Camilo es representado desde sus cualidades militares, y más que nada como un estratega en combate. En clara diferencia, Guevara es expuesto desde sus valores humanos, es decir como hombre disciplinado, entregado a la causa, deseoso de aprender y perfeccionarse permanentenmente, participativo socialmente, 


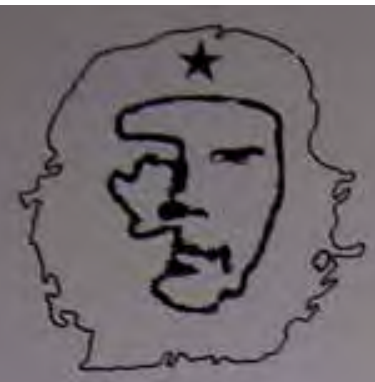

Uno de los rasgos distintivos de la personalidad de Ernesto Che Guevara eran sus ansias de aprender. Leia constantemente a pesar de la gran presión de trabajo y de las responsabilidades que desempeñaba. Era дmante de la literatura en sus más diversos géneras.

Cédula de la exposición permanente del Centro Cultural Casa del Che. Imagen propiedad de los autores.

realizador de trabajos voluntarios, etc. Todos estos aspectos son graficados en el Centro Cultural Casa del Che, y representan las máximas características que el Estado quiere difundir en la ciudadanía cubana.

Lo anterior, demuestra que los cuatro museos desde diversas perspectivas, apuntan a consolidar un discurso que retoma la idea guevarista de que la construcción y vigencia del socialismo además de constituir una transformación institucional y estructural, demanda simultáneamente un cambio en la subjetividad de las poblaciones. Esto es una actitud solidaria y comprometida con la causa por parte de las personas (Lizarraga 2016). Siguiendo a Guevara, no puede conformarse la revolución, sin lo institucional y lo humano que lo acompañe, y los cuatro museos lo exponen explícitamente y de forma articulada. Sus discursos integran dicha problemática desde una doble perspectiva: una posición particular y localista -el de dos sujetos protagonistas de las dos independencias, y su vínculo con el proceso y estructura revolucionaria-, y desde un eje pasado-presente donde ese pasado glorioso se resignifica en las identidades actuales de La Habana. 
Para finalizar es importante remarcar que los museos analizados, contienen discursos caracterizados por la informalidad discursiva, debido a que integran en su mayoría frases, ideas y discursos de Fidel Castro y José Martí principalmente. En esto, prima el vínculo narrativo entre el pasado y presente desde una lógica conmemorativa que mantiene vigentes las ideas revolucionarias, para construir un presente de nuevas generaciones que no han sido partícipes de ese proceso y lo consideran lejano. No hay que olvidar que estos discursos son siempre desde la mirada estatal, y contienen poca reflexión y reinterpretación actualizada de este largo proceso que marcó a la historia cubana.

\section{Los discursos museológicos de la Revolución frente a un futuro de cambios}

Cuba está atravesando un inevitable proceso de apertura socioeconómica. Apertura que se debe en parte, a las reformas enunciadas en los Lineamientos de la Política Económica y Social, aprobados por el Partido Comunista Cubano en abril de 2011, y desarrollados posteriormente por el gobierno de Raúl Castro. Esto está generando evidentes reestructuraciones sociales y productivas, que aumentan y visibilizan la influencia de lo internacional en la vida de muchos cubanos, y que se exterioriza por medio de remesas, turismo y venta de servicios, entre otras cosas (Martínez 2012).

Específicamente en lo turístico, Cuba y en particular la ciudad de La Habana ha tenido desde que los presidentes Obama y Castro reanudaron relaciones, un incremento récord de visitas internacionales. Un caso a remarcar es que en el momento en el que se realizó el estudio arribó después de 50 años, el crucero Adonia de la Compañía Fathom -filial de Carnival-, proveniente de Estados Unidos. Esto generó una nueva etapa en el turismo internacional, que trae aparejado una profunda reconsideración y reestructuración en el ámbito patrimonial y cultural, donde lo museológico juega un papel clave.

Estos nuevos desafíos, llevan a la isla a posicionarse desde un lugar de participación activa en la política y economía internacional, pero tratando de no perder su base ideológica histórica. El Estado cubano en este proceso aspira mantener actualizados los discursos museológicos, con el fin de conservar vivo el espíritu que generó y mantuvo al sistema tantos años. El reto es cómo concretar dicha actualización. Siguiendo a Fernando Martínez, la isla se encuentra ante un claro enfrentamiento cultural, que tiene que ver con dos maneras de entender el mundo: el capitalismo y el socialismo (Martínez 2016). El primero se encuentra reforzado por una constante y cotidiana propaganda mundial sobre la forma más adecuada y correcta de vivir. Su campo de batalla está en la vida cotidiana, en las relaciones sociales, y en la idea de un poder y capital económico que le permite a cualquier individuo consumir con libertad.

Por otro lado, el socialismo subsiste en la militancia de una cultura que intenta abrir espacios de subjetividades y habilidades humanas. Allí se valoriza la creatividad y originalidad para enfrentar las escaseces y dificultades de permanecer al margen del poder económico mundial (Martínez 2012). En estos dos campos se encuentran los museos analizados, posicionándose como bastiones de defensa ideológica dentro de esa batalla cultural. Sus discursos tienen la finalidad de que los ideales socialistas continúen vigentes, y que a pesar de los procesos de cambios que se avecinan, la población no olvide los derechos sociales, económicos y políticos adquiridos tras el triunfo revolucionario de 1959. Para ello, se representan los grandes costos y lucha por obtenerlos, y lo más importante, transmiten un ideal de ciudadano que protege esos logros a través de una fuerte conciencia ideológica.

\section{Reflexiones finales}

En este trabajo se expuso una propuesta metodológica para analizar discursos curatoriales, que combinó el análisis crítico del discurso, la hermenéutica y la fenomenología. Una vez que se describieron los espacios museales seleccionados, se procedió a desarrollar la 
metodología. Ésta consistió en tres pasos: el primero analizó la estructura expositiva para comprender la composición discursiva de las exposiciones museográficas. En el segundo paso, identificar el repertorio argumentativo, es decir profundizar en el contenido discursivo de las exposiciones. Finalmente, el tercero estuvo destinado al análisis de la experiencia museal en su conjunto.

Aplicando esta metodología se obtuvo un mayor conocimiento sobre la construcción y resignificación identitaria que actualmente se está llevando a cabo en los museos de La Habana. Esto es, a través de un complejo discurso que toma al pasado emancipador, y a personajes claves como José Martí y Ernesto Che Guevara como ejemplo de ciudadano patriótico y de idiosincrasia social. La información recopilada demostró que el estudio de las exposiciones museológicas y sus discursos, presentan buenas herramientas para conocer la construcción de identidades colectivas de una región, y como fuentes de datos que enriquecen a los estudios sociales y culturales contemporáneos. Con esto, entendemos que los museos comprende una praxis social propia de la sociedad en la que se encuentra; siendo el museo un espacio social, donde se reconfiguran identidades y alteridades, y donde se hacen explícitas las concepciones estatales sobre estos temas.

A modo de cierre, este análisis buscó desde un ejercicio museológico concreto, afianzar la idea de una museología que no siempre sea entendida desde una perspectiva práctica y técnica, sino que también comprende un campo que puede teorizar y reflexionar sobre temas patrimoniales, identitarios y culturales. Además de demostrar que los museos no son espacios pasivos, sino que tiene un rol activo en los lineamientos ideológicos de los Estados contemporáneos. Queda en un futuro analizar cómo estos mensajes son percibidos y negociados por la población habanera, para conocer en su totalidad el ejercicio de comunicación y reflexión museológica.

\section{Agradecimientos}

A los museólogos de La Habana, que abrieron sus puertas solidariamente e hicieron posible este trabajo.

\section{Bibliografía}

Barbera N. y A. Inciarte 2012 Fenomenología y hermenéutica: dos perspectivas para estudiar las ciencias sociales y humanas. Multiciencias 12 (2):199-205

Gadamer H. G. 1994 Verdad y método II. Editorial Sígueme, Salamanca.

-- 2007 El giro hermenéutico. Ediciones Cátedra Teorema, Madrid.

García J. 2014 La labor museológica de la Revolución cubana y el proceso de transformación en la proyección social de los museos en Cuba. Intervención 5 (9): 65-75.

Habermas J. 1970 A Review of Gadamer's truth and Method. En Understanding and Social Inquiry, editado por F. Dallmayr y Th. McCarthy, pp. 335-363. Notre Dame Press, Indiana.

Heidegger M. 1971 El ser y el tiempo, traducción de José Gaos, Fondo de Cultura Económica, Ciudad de México.

Husserl E. 1984 Crisis de las ciencias europeas y la fenomenología trascendental. Ediciones Folios, Ciudad de México.

Íñiguez L. 2003 El análisis del discurso en las ciencias sociales: variedades, tradiciones y práctica. En Análisis del discurso. Manual para las ciencias sociales, editado por L. Íñiguez Rueda, pp. 83-124. Editorial OUC, Barcelona.

Íñiguez L. y C. Antaki 1994 El análisis del discurso en psicología social. Boletín de psicología 44:57-75.

Ley No. 106/2009 Gaceta Oficial de la República de Cuba, 13 de agosto de 2009.

Lizarraga F. 2016 El che, el cerebro de la revolución, Hemisferio Izquierdo: 6, documento electrónico disponible en [http://www.hemisferioizquierdo.uy/single-post/2016/10/07/El-Che-el"cerebro"-de-la-revolución], consultado en octubre de 2016. 
Martín L. y R. Whittaker (eds.) 1998 Poder decir o El poder de los discursos. Arrecife Producciones, Madrid.

Merleau-Ponty, M. 1997 Fenomenología de la percepción. Editorial Península, Barcelona.

Morales J. T. 2011 fenomenología y hermenéutica como epistemología de la investigación. Revista paradigma $32(2): 7-22$.

Morse, J. 2003 Asuntos críticos en los métodos de investigación cualitativa. Editorial Universidad de Antioquia, Medellín.

Mosco, A. 2012 Metodología interpretativa para la formulación y desarrollo de guiones para exposiciones. Tesis de maestría. Escuela Nacional de Conservación, Restauración y Museografía Manuel del Castillo Negrete, INAH, México.

Pearce, S. 1994 Objects as meaning; or narrating the past. En Interpreting Objects and Collections, editado por Susan Pearce, pp. 19-29. Routledge, Nueva York.

Potter J. y M. Wetherell 1987 Discourse and Social Psychology. Sage, Londres.

Ricoeur P. 2006 Teoría de la interpretación. Discursos y excedente de sentido. Siglo XXI Editores, Ciudad de México.

Strauss A. y J. Corbin 2002 Bases de la investigación cualitativa: técnicas y procedimientos para desarrollar la teoría fundamentada. Colombia: Editorial Universidad de Antioquia, Medellín.

Wetherell M. y J. Potter 1996 El análisis del discurso y la identificación de los repertorios interpretativos. En Psicologías, discursos y poder, editado por A. Gordo y J. Linaza, pp. 63-78. Visor, Madrid. 